\title{
Non-Neoplastic Tracheal Disorder
}

National Cancer Institute

\section{Source}

National Cancer Institute. Non-Neoplastic Tracheal Disorder. NCI Thesaurus. Code C35753.

A non-neoplastic disorder that affects the trachea. Representative examples include tracheitis, tracheal agenesis, and tracheal atresia. 